Article

\title{
Investigating the Relation between Walkability and the Changes in Pedestrian Policy through Wearable Sensing
}

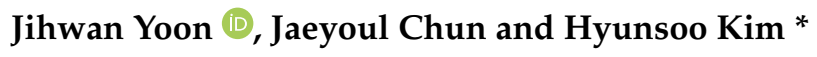 \\ Department of Architectural Engineering, Dankook University, 152 Jukjeon-ro, Suji-gu, Yongin-si 16890, \\ Gyeonggi-do, Korea; jihwan@dankook.ac.kr (J.Y.); jaeyoul@dankook.ac.kr (J.C.) \\ * Correspondence: hkim13@dankook.ac.kr
}

Received: 9 November 2020; Accepted: 10 December 2020; Published: 14 December 2020

\begin{abstract}
Since the enhancement of pedestrian rights, various pedestrian-related laws and policies have been implemented to enhance walkability. However, although laws and policies have been implemented to improve walkability, the quantitative measurement of walkability was insufficient in previous studies. Therefore, in this study, we analyzed the walkability of three experimental sites with different built periods using a wearable sensor. This study aims to overcome the limitations of previous studies and to confirm the applicability of pedestrian-related laws and policies. Accordingly, 30 subjects were recruited to participate in the experiment. Gait data were collected using the inertial measurement unit sensor of a smartphone. Based on the collected data, a similarity index was calculated by comparing the reference gait with the gait at each experimental site using dynamic time warping. The closer the calculated result is to 0 , the higher is the similarity, that is, the walkability is high. The results of this study can be used as both a monitoring tool for pedestrian policy and an actual condition survey tool. Moreover, these results are expected to contribute to a pedestrian evaluation system using citizen sensing in smart cities in the future.
\end{abstract}

Keywords: pedestrian policy; walkability; wearable sensing; IMU; DTW

\section{Introduction}

\section{Background and Purpose of Study}

Pedestrian traffic is the starting point for all traffic. Litman [1] and Abley [2] discussed the way pedestrians walk and the corresponding benefits to society. They defined the concepts of 'walking' and "walkability (walking quality)" and emphasized the importance of pedestrians walking. Historically, specific improvements to the guarantee of pedestrian rights began in the 1960s in Europe ("Traffic in Towns: A study of the long-term problems of traffic in urban areas", 1963). Since then, this field of research has expanded to include traffic calming areas, home zones and meeting zones. The right to walk was clearly stated when the European Parliament enacted and announced the European Charter of Pedestrian Rights [3]. The movement to build walkable cities and walkable communities has been growing since the 2000s.

Albeit later than in Europe, citizens' right to walk began to attract increasing interest in Korea. In the early 1990s, the term "pedestrian right" was officially used in Korea [4]. Then, in 1997, the Seoul Metropolitan Government enacted a sole pedestrian ordinance. Later in 1998, the "First Basic Plan for Walking Environment" was implemented. In 2005, the "Act on the Promotion of Transportation Convenience for the Vulnerable" (the Ministry of Land, Infrastructure and Transport) was enacted to improve the walking environment for the elderly, pregnant women and the disabled so that they could move safely and conveniently [5]. In the same year, the "Second Basic Plan for the Walking Environment" was implemented to promote citizens' pedestrian rights. Finally, with the enactment of 
the "Act on Pedestrian Safety and Convenience Promotion" in 2012, pedestrian-related policies and plans began to be implemented nationwide [6].

As such, several local governments, including the Seoul Metropolitan Government, continue to make efforts to improve walkability in cities based on laws and policy measures. However, there is a relative scarcity of analysis on the improvement of walkability in accordance with the changes in the pedestrian policy system. The walkability must be measured before the analysis of the changes in walkability due to the changes in the pedestrian policy system.

Studies related to the measurement of walkability [7] and the derivation of the indicators that can evaluate the walking environment [8-10] have been conducted. Based on the above studies, people developed a lot of method to measure the waling environment. These methods can be classified into subjective and objective methods. The subjective method involves real pedestrians filling out questionnaires. The evaluation method through the questionnaire is user-centered in that it evaluates the walking environment experienced by an actual pedestrian. However, there is a limit to the individual propensity or cognitive characteristics of the subject being revealed in the response.

The objective method involves measurement using proven evaluation tools. Professional investigators use evaluation tools to evaluate walkability, rather than through an evaluation by actual pedestrians. Daamen and Hoogendorn [11] and Singh [12] divided the various factors affecting the walking path into internal (i.e., age, gender, risk exposure propensity, delay tolerance, etc.) and external (i.e., the scale and type of walking facilities, the types of road and walking path, the use of low-rise buildings around the walking paths, the complexity and length of routes, etc.) types. Clifton et al. [13] developed the walking environment data scan called PEDS, which consists of 31 items. Hoehner et al. [14] and Blecic et al. [15] used a developed measurement tool, active neighborhood checklist (ANC), to measure the walkability on a target road and measured the reliability based on the results. The advantage of this type of walkability assessment is that it can evaluate the walking environment quantitatively based on pre-defined items. However, the person using the actual walking environment cannot directly reflect their assessments. Because trained surveyors assess the environment. Thus, measures are required to reflect actual pedestrians in the evaluation system and to minimize their bias through subjective characteristics, to compensate for these limitations.

Recent advances in information technology and wearable equipment have led to the commercialization of the ability to collect and analyze data related to human behavior; moreover, human-centric sensing technology that deduces various kinds of information through interactions with human behavior patterns has drawn attention $[16,17]$. The characteristics of gait (that is, a person's pattern of walking), such as pedestrian stability and consistency, may vary depending on the external environment. They are measured using wearable equipment in several studies $[18,19]$.

Wearable sensors can monitor data on responses through the measurements of continuous behavior, even if they do not collect data by intention [20-24]. Among various sensors, a three-axis acceleration sensor (inertial measurement unit (IMU)) is used for gait recognition [25,26]. Data are collected using IMU-sensor-embedded smartphones carried by most pedestrians to enhance the generality of human behavior patterns and studies related to pedestrian measurements.

In general, human behavior is characterized by the desire to maintain homeostasis [27]. In the case of gait, the stability of the body varies continuously with movement and it is affected by the external environment [28-30]. In this study, pedestrian stability represents a constant variability in physical stability, which is calculated through three-axis acceleration using an IMU sensor located on a subject's right leg. The stability is also indicated by the consistency of the gait pattern of pedestrian. [31-33]. If a pedestrian is walking on a well-managed road without obstacles, such as a paved promenade in a sound park, the gait cycle may be constant. In contrast, if a pedestrian is walking on a road with a car passing by or with other pedestrians, then the gait cycle may be unstable. Because the pedestrian's walking needs to be changed or adjusted according to the changes in the walking environment. In this regard, pedestrian stability can be considered higher when the gait cycle is repeated and the gait is less disruptive. 
Based on this background, this study is conducted through the following sequence of steps. First, policy changes related to Korea are considered to improve the pedestrians' right to walk. Second, urban environments built at a time when policy changes are evident are selected. Third, data on gait patterns are collected in the individual urban environments. Fourth, the collected data are analyzed to calculate the repeatability of the gait pattern and quantify it. Finally, the changes in the system are compared using the gait patterns of the actual pedestrians and their associations are examined.

The pedestrian-related policy system has been developed to supplement and enhance walkability over time. Therefore, this study can provide a way to confirm the actual enhancement of pedestrian walkability in accordance with the changes in the pedestrian policy system. In addition, indirect measurements of the built environment under policy changes can provide methods of monitoring the environment on a continuous basis. Continuous and immediate monitoring using sensing is expected to contribute to the provision of smart services using sensing data in the future.

\section{Experiment Design}

\subsection{Hypothesis Setting}

Policy changes related to pedestrian rights were implemented to ensure pedestrian walkability. Therefore, this study aims to ensure that changes in the walking environment caused by policy changes lead to changes in pedestrian walkability. In other words, this study quantifies gait patterns collected through IMU sensors built into smartphones and examines the relationship between their values and the changes in the walking environment according to policy changes. To this end, the following assumptions were established and verified.

- Hypothesis setting: The changes in the walking environment caused by policy changes cause changes in the gait patterns of pedestrians. The degree of change can be quantitatively compared.

\subsection{Selection of Experimental Sites}

Three sites (Sangdaewon-dong, Jeongja-dong and Gwanggyo-dong) were selected for the experiment. The history of Korea's "pedestrian rights" can be divided into three major periods: the beginning of the right to walk (the early 1990s), the subsequent period of the right to walk (from the late 1990s to the early 2000s) and the final period of the right to walk (from the late 2000s). Therefore, the criteria for selecting the experimental sites were also based on cities formed during the three aforementioned periods and the experiment sites were compared based on the laws and policies. The Table 1 shows the details of policy changes in three sites.

Prior to the 1990s, Korea's urban design prioritized the speed and convenience of automobiles and traffic policies and legislation were emphasized. Intersections without crosswalks and facilities that encroached on walking spaces represented Korea's walking environment at that time. In the early 1990s, the concept of "pedestrian rights" was introduced; subsequently, civic groups have led efforts to improve pedestrians' walking rights $[4,6]$.

In the late 1990s and mid-2000s, when pedestrian rights were becoming increasingly popular. Through enacting the pedestrian ordinance or establishing the walking environment basic plans, local government made considerable progress. Since the late 2000s, the government has felt the need to enact a plan at the national level; accordingly, the "ACT ON PROMOTION OF THE TRANSPORTATION CONVENIENCE OF MOBILITY DISADVANTAGED PERSONS" also included enhancements of the convenience and safety of pedestrians. Subsequently, the "PEDESTRIAN SAFETY ANDCONVENIENCE ENHANCEMENT ACT" was enacted and promulgated after several discussions between the central and local governments. This is significant in that the pedestrian rights are legally defined and guaranteed by the central and local governments [34]. The experimental sites were selected in cities that were built during the different periods of establishment and promulgation of pedestrian rights. Thus, Sangdaewon-dong Site1 (1970 ), Jeongja-dong Site2 (1994 ) and Gwanggyo-dong Site3 (2010 ) were selected to conduct the experiments. 
Table 1. Process of Changes in Pedestrian Rights in Korea and the Built Period of Each of the Experimental Sites.

\begin{tabular}{|c|c|c|}
\hline Classify & Pedestrian-Related Laws and Policies and Main Contents & Experimental Sites (Built Period) \\
\hline 1962.01 .01 & ROAD ACT & \multirow{4}{*}{ Sangdaewon-dong (1970 ) } \\
\hline 1962.01 .20 & ROAD TRAFFIC ACT & \\
\hline 1979.12.28 & TRAFFIC SAFETY ACT & \\
\hline 1993-1994 & A civic group led the movement for the right to walk. & \\
\hline 1994-1997 & $\begin{array}{l}\text { - } \quad \text { Adopting the District Transportation } \\
\text { Improvement Project } \\
\text { - } \quad \text { Legislation of child protection zones }\end{array}$ & \multirow{3}{*}{ Jeongja-dong (1994 ) } \\
\hline 1996-1998 & $\begin{array}{l}\text { - Promoting the movement to make Seoul want to walk } \\
\text { First establishment of the Seoul Metropolitan Pedestrian } \\
\text { Ordinance (Basic Ordinance on Securing Pedestrian } \\
\text { Rights and Improving the Walking Environment } \\
\text { in Seoul) }\end{array}$ & \\
\hline 1998-2005 & $\begin{array}{l}\text { - Gwanghwamun crosswalk installation as a crosswalk } \\
\text { installation movement } \\
\text { The enactment of gait ordinances by local self-governing } \\
\text { organizations such as Jeju City in 1999, Busan and } \\
\text { Gwangju City in } 2000 \text { and Suwon and Mokpo City } \\
\text { in } 2001\end{array}$ & \\
\hline $\begin{array}{c}2005 \\
2007-2012\end{array}$ & $\begin{array}{l}\text { - } \quad \text { ACT ON PROMOTION OF THE TRANSPORTATION } \\
\text { CONVENIENCE OF MOBILITY } \\
\text { DISADVANTAGED PERSONS1 }\end{array}$ & \multirow{3}{*}{ Gwanggyo-dong (2010 ) } \\
\hline 2009 & $\begin{array}{l}\text { - } \quad \text { SUSTAINABLE TRANSPORTATION LOGISTICS } \\
\text { DEVELOPMENT ACT }\end{array}$ & \\
\hline 2012 & $\begin{array}{l}\text { - } \quad \text { PEDESTRIAN SAFETY AND CONVENIENCE } \\
\text { ENHANCEMENT ACT }\end{array}$ & \\
\hline
\end{tabular}

Table 2 presents a map of the experimental sites and the features of the roads at each of the sites. Site1 of Sangdaewon-dong was built in the 1970s. Currently, it is classified as an old city area in the 2030 Seongnam City Basic Plan for Urban and Residential Environment Improvement. It can be observed from the general characteristics of Sangdaewon-dong that, when it was built, road planning focused on automobiles was prioritized over pedestrian-oriented roads. Therefore, the roads were not properly separated. Vehicles were parked and they stopped frequently on roads that were mixed-use roads. Moreover, there were heaps of neglected garbage that could obstruct walking and cracks also occurred as time passed. The average width of the road is approximately 3-6 m. If it is intended only for walking, it is sufficiently wide. However, there are elements that obstruct walking on the road, such as vehicles and cracks. Hence, the actual width of the road that pedestrians can use is reduced, which would make walking uncomfortable. 
Table 2. Map of Experimental Sites and Features of Each of the Sites.

\begin{tabular}{|c|c|c|c|c|c|c|c|}
\hline \multicolumn{2}{|c|}{ Classify } & \multicolumn{2}{|c|}{$\begin{array}{c}\text { Sangdaewon-Dong } \\
\text { (Site1) }\end{array}$} & \multicolumn{2}{|c|}{$\begin{array}{l}\text { Jeongja-Dong } \\
\text { (Site2) }\end{array}$} & \multicolumn{2}{|c|}{$\begin{array}{c}\text { Gwanggyo-Dong } \\
\text { (Site3) }\end{array}$} \\
\hline \multicolumn{2}{|c|}{$\begin{array}{c}\text { Map of } \\
\text { experimental sites }\end{array}$} & 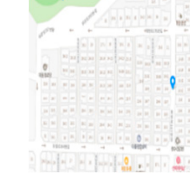 & $\because \div$ & 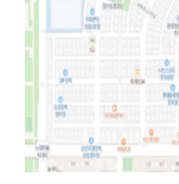 & & $\begin{array}{l}= \\
\Rightarrow=3 \\
=3 \div\end{array}$ & \\
\hline \multicolumn{2}{|c|}{ Built period } & \multicolumn{2}{|c|}{$1970 \sim$} & \multicolumn{2}{|c|}{ 1994 } & \multicolumn{2}{|c|}{ 2010 } \\
\hline \multicolumn{2}{|c|}{$\begin{array}{l}\text { Development } \\
\text { method }\end{array}$} & \multicolumn{2}{|c|}{ Land readjustment } & Land de & opmer & \multicolumn{2}{|c|}{ New city developmen } \\
\hline \multirow{3}{*}{$\begin{array}{l}\text { Status } \\
\quad(\mathrm{m})\end{array}$} & $\begin{array}{l}\text { Road } \\
\text { width }\end{array}$ & \multicolumn{2}{|c|}{$3-6$} & & & \multicolumn{2}{|c|}{$6-20$} \\
\hline & $\begin{array}{l}\text { Sidewalk } \\
\text { width }\end{array}$ & \multicolumn{2}{|c|}{-} & & & \multicolumn{2}{|c|}{$4-15$} \\
\hline & & Description & Figure & Description & Figu & Description & Figure \\
\hline \multirow{3}{*}{\multicolumn{2}{|c|}{$\begin{array}{c}\text { Road } \\
\text { Characteristics }\end{array}$}} & $\begin{array}{c}\text { Illegal } \\
\text { parking on } \\
\text { sidewalk }\end{array}$ & & $\begin{array}{c}\text { Separated } \\
\text { road } \\
\text { (Partly) }\end{array}$ & & $\begin{array}{l}\text { Separated } \\
\text { road } \\
\text { (Complete) }\end{array}$ & \\
\hline & & $\begin{array}{l}\text { Walking } \\
\text { obstruction } \\
\text { elements }\end{array}$ & & $\begin{array}{c}\text { Illegal } \\
\text { parking on } \\
\text { sidewalk }\end{array}$ & & $\begin{array}{l}\text { Wide } \\
\text { pedestrian } \\
\text { Road }\end{array}$ & \\
\hline & & $\begin{array}{l}\text { Mixed-use } \\
\text { road }\end{array}$ & & $\begin{array}{l}\text { Mixed-use } \\
\text { wide road }\end{array}$ & & $\begin{array}{l}\text { Space for } \\
\text { walking } \\
\text { only }\end{array}$ & \\
\hline
\end{tabular}

On the other hand, it was confirmed that, as the cities Jeongja-dong and Gwanggyo-dong were built relatively recently, the roads were separated. First, Jeongja-dong began to be built in 1994. It has a sufficiently wide pedestrian road of width approximately $3-8 \mathrm{~m}$. As it is a pedestrian-only road, pedestrians can move comfortably and safely without obstructing vehicles. However, approximately $20 \%$ of the entire road in Jeongja-dong is a mixed-use road like Sangdaewon-dong. Therefore, vehicles are illegally parked and stopped across the sidewalk.

Finally, the characteristics of Gwanggyo-dong are as follows: It is the most recent city among the three experimental sites and it was built in the 2010s. The roads for walking and those for electric scooters and bicycles were separated. Compared with the previous two cities, few factors can cause discomfort in walking. Furthermore, even if there are factors that can obstruct walking, the walking path is sufficiently wide; hence, such factors would not have a significant effect on walking.

As mentioned earlier, the three experimental sites were built at different times; moreover, they were based on pedestrian-related policies, systems and laws that were enacted and implemented when the cities were built. Due to the influence of these laws and policies, the walking environments of the experimental sites appear to have different physical characteristics.

\subsection{Participants}

Thirty participants (18 male and 12 female subjects) were recruited to conduct the experiment. The recruited participants were sturdy young people in their 20s, 30s, or 40s, so that they had no discomfort in walking. All the participants could participate in the experiment without external 
assistance because they had no discomfort in walking and had normal vision and mobility. The details of the participants are listed in Table 3.

Table 3. Participant Information.

\begin{tabular}{cccc}
\hline \multicolumn{2}{c}{ Information } & $\begin{array}{c}\text { Male } \\
\text { (18 Persons) }\end{array}$ & $\begin{array}{c}\text { Female } \\
\text { (12 Persons) }\end{array}$ \\
\hline Height $(\mathrm{cm})$ & Mean (SD) & $172.29(5.47)$ & $161.84(6.14)$ \\
Weight $(\mathrm{kg})$ & Mean (SD) & $67.34(7.89)$ & $54.46(5.85)$ \\
Shoe Size (mm) & Mean (SD) & $262.5(7.25)$ & $224.34(8.23)$ \\
Age (years) & Mean (SD) & $29.82(8.38)$ & $26.34(6.28)$ \\
\hline
\end{tabular}

\subsection{Experimental Procedure}

The experimental equipment was worn as shown in Figure 1 to collect the data for the experiment. First, a smartphone (Model: Samsung Galaxy Note 8) was fixed in the front right pockets of the pedestrians' pants to minimize its movement during walking.

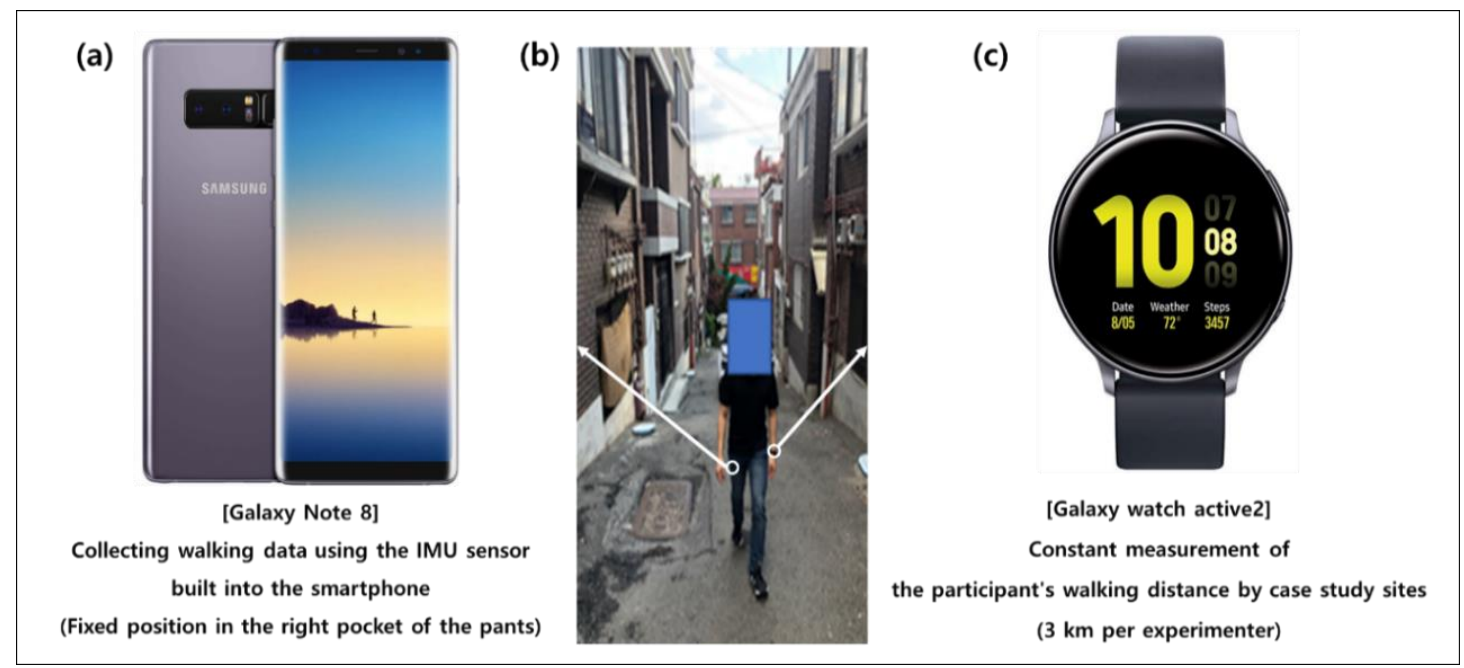

Figure 1. Data collection: (a) Smartphone used for data collection; (b) the image of a participant walking; (c) electronic clock used for distance measurement.

With respect to Jeongja-dong, Sangdaewon-dong is $10 \mathrm{~km}$ away and Gwanggyo-dong is $12 \mathrm{~km}$ away. Therefore, the participants had to move to the different experimental sites for data measurement. It was difficult to conduct all the experiments on a single day. Moreover, a sunny day with no rain that did not obstruct walking as much as possible was preferred; hence, the experiment was conducted for approximately 1.5 months from 10 May to 23 June in 2020. Owing to the influence of the weather and the limit on the number of equipment, the experiment was conducted with up to five participants per day and the goal was to acquire gait data for 30 people at each site. The participants walked $3 \mathrm{~km}$ at each site and the number of gait patterns required at this time was different depending on the walking environment of the site. When the participants walked $3 \mathrm{~km}$ on the playground track, which is the reference gait section, approximately 6000 steps were taken on average. Finally, the total numbers of walking steps for the 30 people at each site were summed and compared. The numbers of steps were measured as 190,204, 181,024 and 178,022 in Sangdaewon-dong, Jeongja-dong and Gwanggyo-dong, respectively. The analysis was conducted using the data and number of steps obtained in this experiment and accordingly, the walkability at each experiment site was examined.

In this study, the participants collected gait data using a smartphone. The reasons for choosing a smartphone among various wearable devices are as follows. First, data can be collected through a three-axis acceleration (IMU) sensor built into the smartphone $[25,26]$. Second, most smartphones have 
the ability to measure distances. The location of distance walked by the participant can be measured using the global positioning system (GPS) sensor of the smartphone [35,36]. Third, the smartphone can be interlocked with a smart device, such as the Galaxy Watch Active2, in Figure 2. In this experiment, the distance was measured by monitoring the Galaxy Watch linked to the smartphone and measuring the distance walked by the participant. Finally, smartphones can transmit and receive data. Therefore, they are expected to be utilized in the field of urban environment monitoring in smart cities in the future.

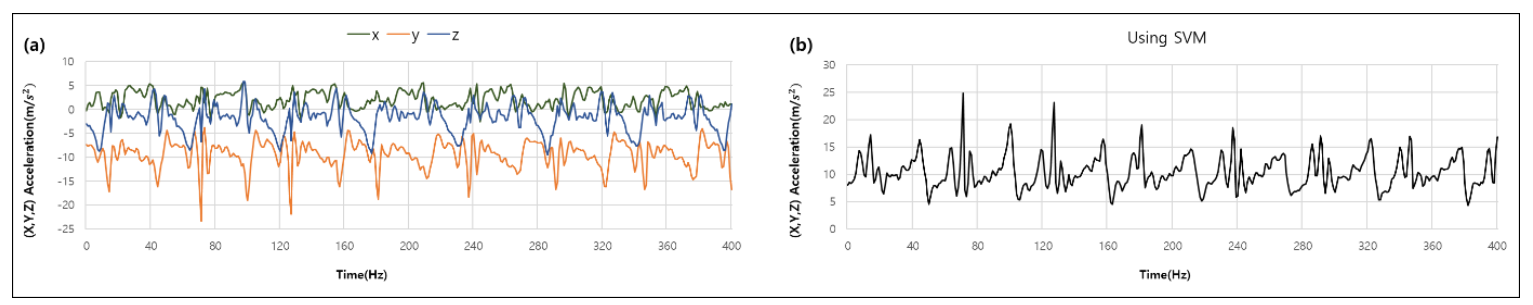

Figure 2. Use of SVM equation: (a) x-, y- and z-axes output values of the acceleration sensor; (b) SVM energy conversion value.

\subsection{Method for Calculating Signal Vector Magnitude (SVM)}

In this study, participants walked at the experimental sites in cities with different built periods and the walking environment differed according to pedestrian laws and policies. The physical movement of the participant is transmitted to the IMU sensor of the smartphone and walking can be analyzed accordingly. Several previous studies have shown that human walking is affected by external environmental conditions $[30,37,38]$. In addition, the more suitable the walking environment is for walking, the more consistent is the gait pattern and similar gait cycles are continuously maintained [31]. In other words, if there is no change in the environment other than the gait (e.g., gait in a controlled laboratory), it can be said that similar gait cycles repeat and remain constant. Conversely, when there are changes in the external environment (e.g., roads with obstacles, garbage, unmanaged surfaces), the similarity of the gait cycles decreases, indicating that the gait pattern may change.

The three-axis acceleration (IMU) sensor in the smartphone generates acceleration data in three directions: $x, y$ and $z$. The output data include not only the components of motion of the upper and lower axes by the step, but also rotational component and twist of the gait direction [26,39]. In addition, in this experiment, as the smartphone is located in the lower right pocket of the participant, its orientation may also affect the sensor. Therefore, it is effective to convert the three-axis acceleration data values into an energy value through an SVM operation and process this value to minimize the aforementioned effect and reduce the computational complexity [40]. The SVM association equation is expressed as follows:

$$
S V M=\sqrt{x^{2}+y^{2}+z^{2}}
$$

where $x$ is $\mathrm{x}$ axis acceleration, $y$ is $\mathrm{y}$ axis acceleration and $z$ is $\mathrm{z}$ axis acceleration.

Figure 2 shows the conversion of the $\mathrm{x}-, \mathrm{y}$ - and $\mathrm{z}$-axes acceleration values collected by the three-axis acceleration sensor into an energy value (SVM). In this study, the experiment was conducted through the following process using the SVM equation.

\subsection{Method for Calculating Dynamic Stability using Dynamic Time Warping (DTW)}

The stability of the walking environment can be judged high if a similar gait pattern is observed continuously [31]. In this study, we used the DTW algorithm to measure gait stability as shown in Figure 3. The DTW algorithm is mainly used in time series analysis for measuring the similarity between two temporal sequences at different speeds. For example, DTW can be used even when a person walks faster than usual in a specific situation or there is acceleration and deceleration during the observation process and gait similarity can be detected [41,42]. DTW is also used in the analysis of changes in people's walking patterns depending on the changes in the road environment $[42,43]$. 


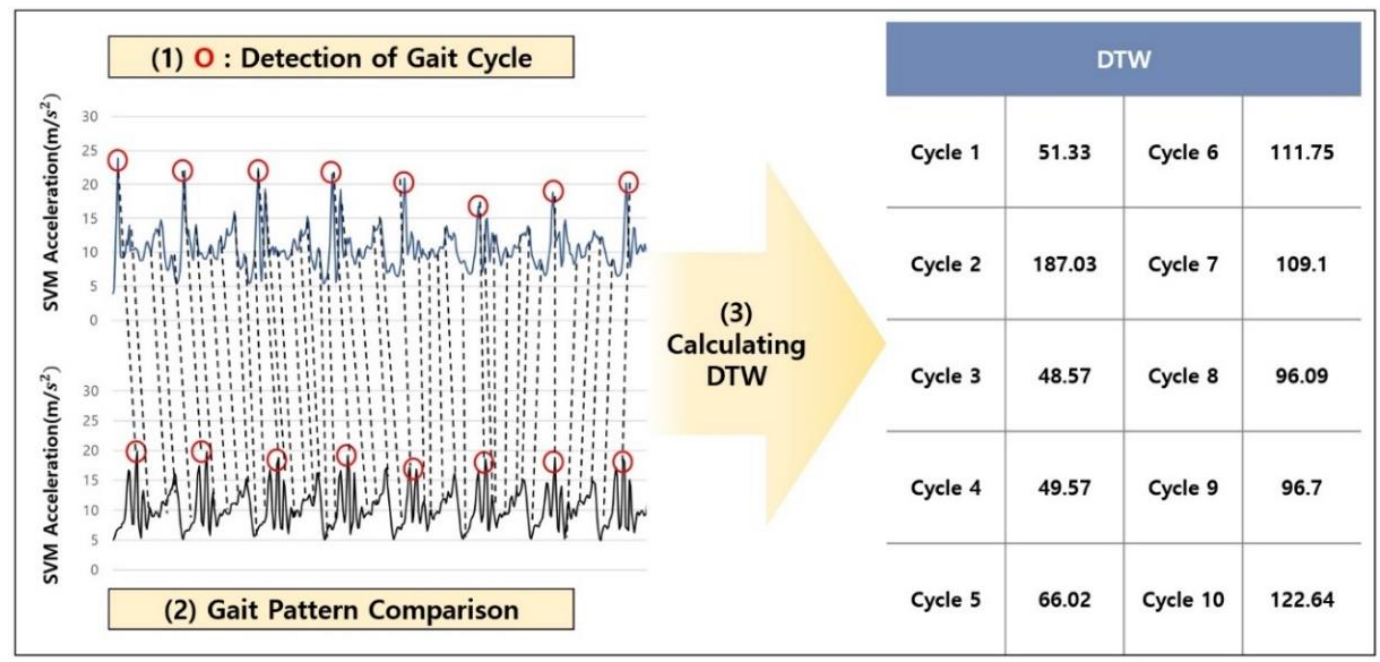

Figure 3. DTW calculation process: (1) Detection of gait cycle, (2) gait pattern comparison, (3) calculating DTW.

That is, DTW can be used to express the degree of change of consecutive strides quantitatively. Therefore, the more the walking is repeated in a certain form, the closer this value is to 0 and the more irregularly the walking is repeated, the larger is the value. Therefore, in this study, after obtaining the gait pattern cycle for each site through the collected gait data, the similarity with the gait cycle of the standard gait was quantitatively expressed using DTW.

Figure 4 shows the process of calculating the similarity quantitatively using DTW. After determining the repeated cycles for two different patterns, the similarity of the cycles is finally expressed as a numeric value by comparing these cycles using the DTW algorithm. In this study, it is possible to express the reference gait and the gaits at each experiment site quantitatively.

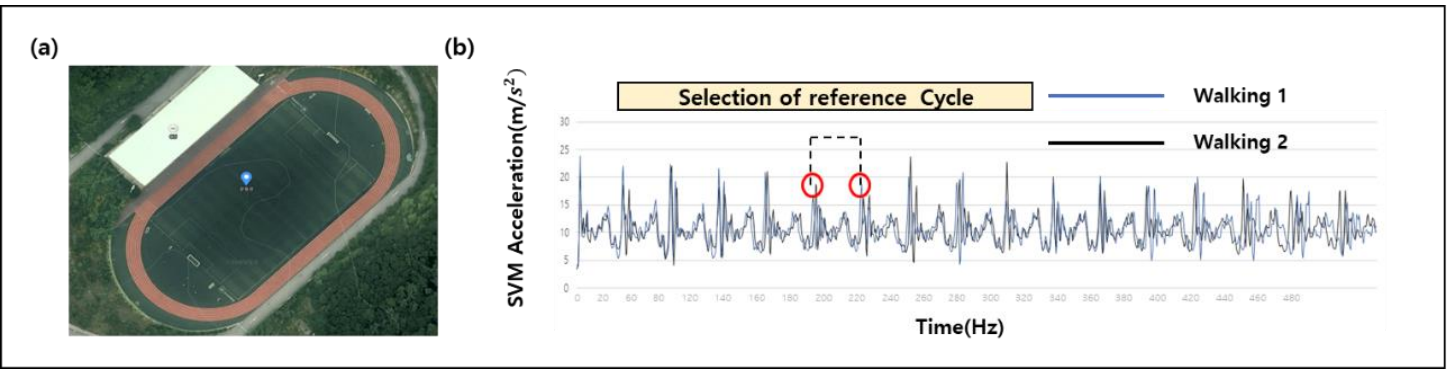

Figure 4. Reference section: (a) Dankook University running track; (b) selection of reference cycle in track.

\subsection{Method for Performing Kolmogorov-Smirnov Test (K-S Test)}

The consistency of the collective gait pattern of pedestrians stimulated by the external environment is measured to have a lower normality than that of pedestrians not stimulated by the external environment [31,37]. Therefore, it is not possible to maintain consistency in walking, which is stimulated by the external environment. In other words, the walkability of the corresponding area can be analyzed by determining whether the gait data of the participants maintain consistency through a normality test.

In previous studies, the Shapiro-Wilk test has been generally used to test the normality of data $[38,39]$. However, in the case of the Shapiro-Wilk test, the data size should be less than 5000 . In the case of this study, as the total numbers of gait cycles of the pedestrians at each site are 190,204, 181,024 and 178,022 steps at Sangdaewon-dong, Jeongja-dong and Gwanggyo-dong, respectively, it is not possible to test normality through the Shapiro-Wilk test. Therefore, in this study, the normality of 
the data was tested using the Kolmogorov-Smirnov test (K-S test), which is used for the representative dataset. Equation (2) is an expression of the $\mathrm{K}-\mathrm{S}$ test.

$$
D=\sup _{x}\left|F_{n}(x)-F(x)\right|
$$

In the above equation, $F_{n}$ is the empirical distribution function for $n$ independent and identically distributed ordinal observations $X_{i}$, defined in Equation (3).

$$
F_{n}(x)=\frac{1}{n} \sum_{i=1}^{n} I_{[-\infty, x]}\left(X_{i}\right)
$$

Consequently, the result of normality evaluation through the K-S test is expressed by $D_{n}$ in Equation (2), where $\sup _{x}$ is the supremum of the set of distances. If the sample originates from distribution $F(x)$, then $D_{n}$ converges to 0 almost surely in the limit when $n$ goes to infinity. Therefore, it is judged that the data have normality, as the above value converges to zero.

\section{Experiment Result and Analysis}

In this chapter, an experiment is performed according to the experimental method described in Chapter 2 and then, analysis is performed using the acquired data. The pedestrian gait patterns can be compared using the SVM formula and quantified using the DTW algorithm. The patterns and DTW for each site (Sangdaewon-dong, Jeongja-dong and Gwanggyo-dong) can be compared and analyzed and accordingly, the research hypothesis established in Chapter 2.1 is verified.

\subsection{Analysis of Gait Patterns Using SVM}

The DTW algorithm compares the degree of similarity. This study aims to obtain the DTW value for each experimental site (Site1, Sangdaewon-dong/Site2, Jeongja-dong/Site3, Gwanggyo-dong). Therefore, a "'reference gait section"' is required for a comparison with each site. The reference section has no obstacles to walking and a section in which pedestrians do not feel discomfort is selected. In this study, the track of the Dankook University playground was selected as the reference gait section. Playground tracks are designed to improve the performance of athletes and the surface of the track provides excellent shock and cushioning capabilities to protect their joints, lowering the risk of injury. In addition, these tracks can reduce muscle stress and support leg movements, making them an ideal choice for gait standards. Therefore, in this study, comparisons were conducted for each site based on the aforementioned playground track.

In this study, the gait data of the $x-, y$ - and $z$-axes collected by the IMU sensor are expressed using the SVM equation. Figure 5 shows the gait data on the track of the Jukjeon campus of Dankook University, which was selected as the reference section, calculated using the SVM equation. The gait pattern can be confirmed through SVM and similar patterns can be observed to be maintained continuously. It can be observed that there is no significant external change and the pedestrian gait pattern tends to be maintained constant at the point where similar walking environments repeatedly appear. As shown in Figure 5, a reference gait cycle is selected for a comparison with the experimental sites.

Figure 6 shows the use of the SVM values for the comparison of the gait patterns in the reference section and at each experimental site. In the reference walking section, it can be observed that similar patterns are repeated in a certain period. In contrast, in the case of Sangdaewon-dong, the maximum value of the SVM, which is the y-axis, varies greatly and the consistency of the pattern tends to decrease. The period of the pattern is also shortened. It can be inferred that a change in walking has occurred due to the existence or occurrence of a factor related to the external environment. On the other hand, in recently built cities, such as Jeongja-dong and Gwanggyo-dong, it can be observed that the gait pattern is consistent with reference walking. In particular, in the case of Gwanggyo-dong, the cycle and pattern most similar to the reference walking can be confirmed. 


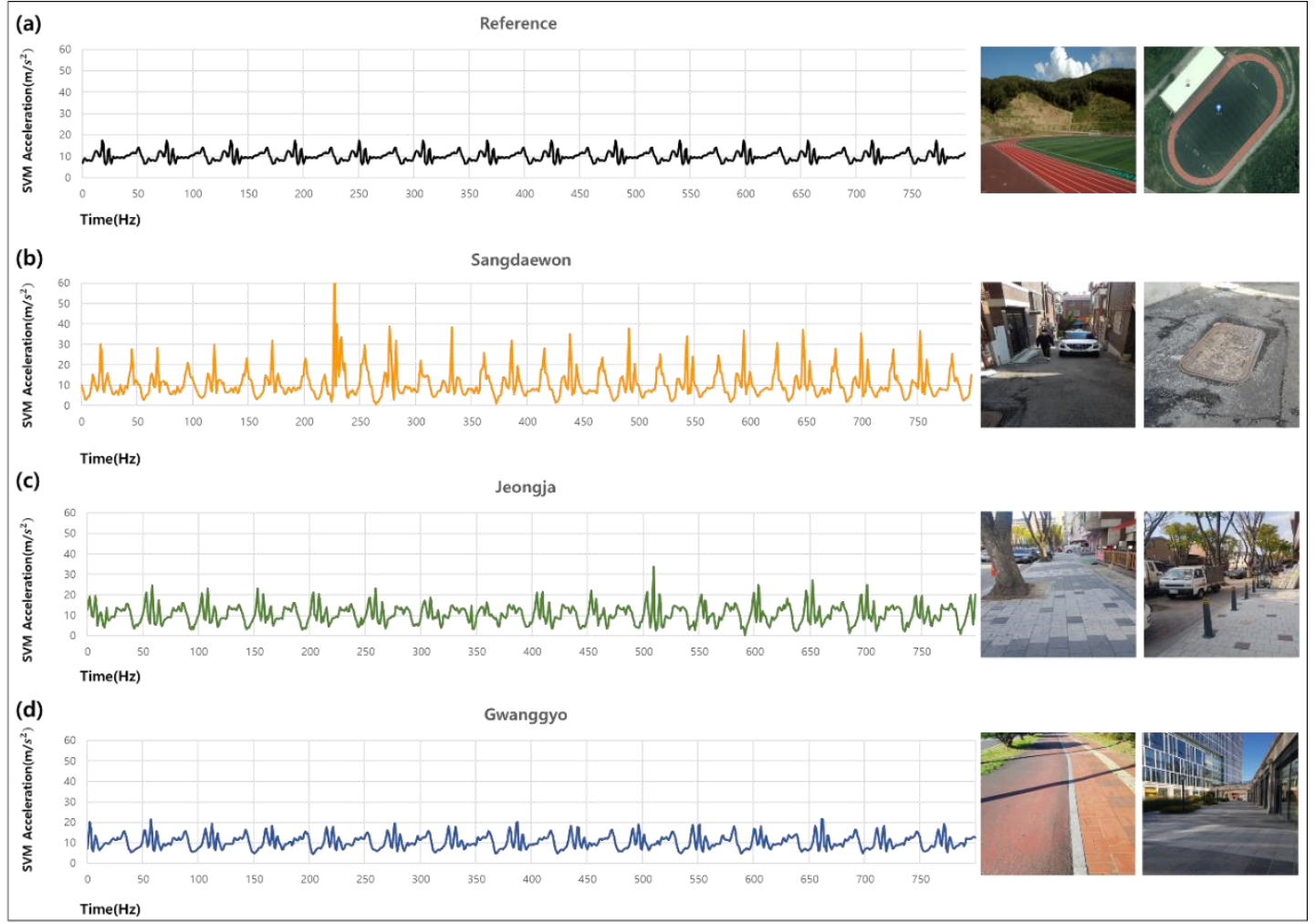

Figure 5. Gait patterns for each case site: (a) Reference section; (b) Sangdaewon-dong; (c) Jeongja-dong; (d) Gwanggyo-dong.

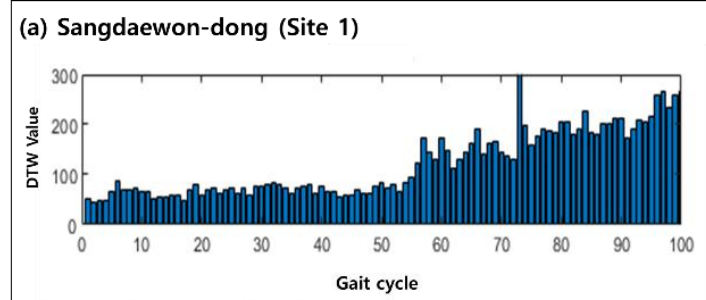

(b) Jeongja-dong (Site 2)
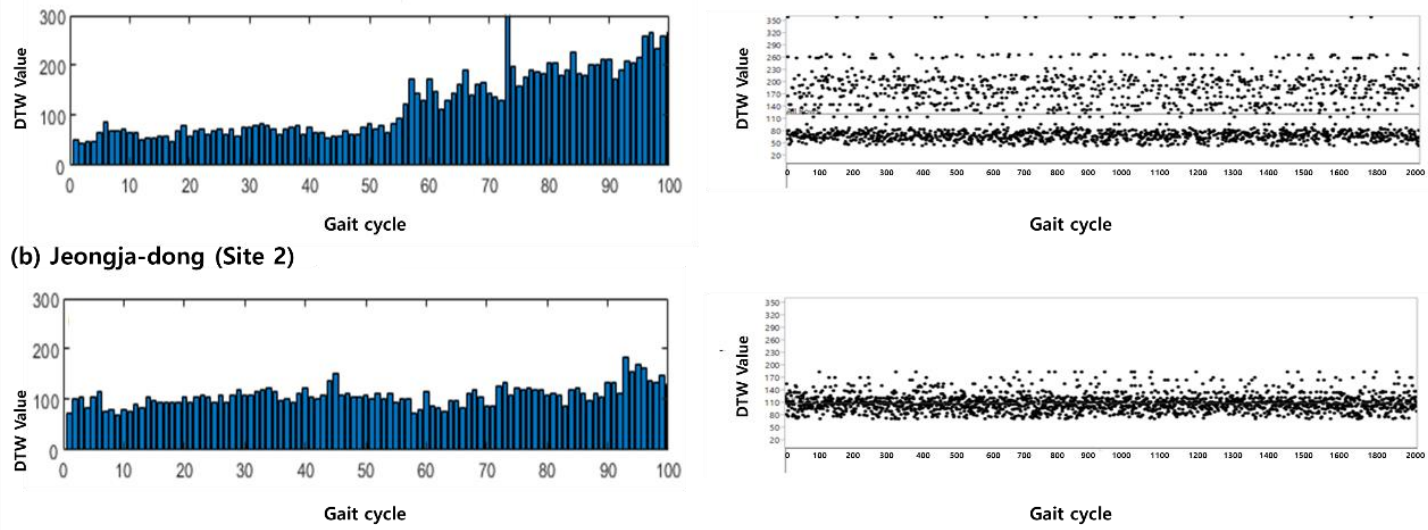

(c) Gwanggyo-dong (Site 3)
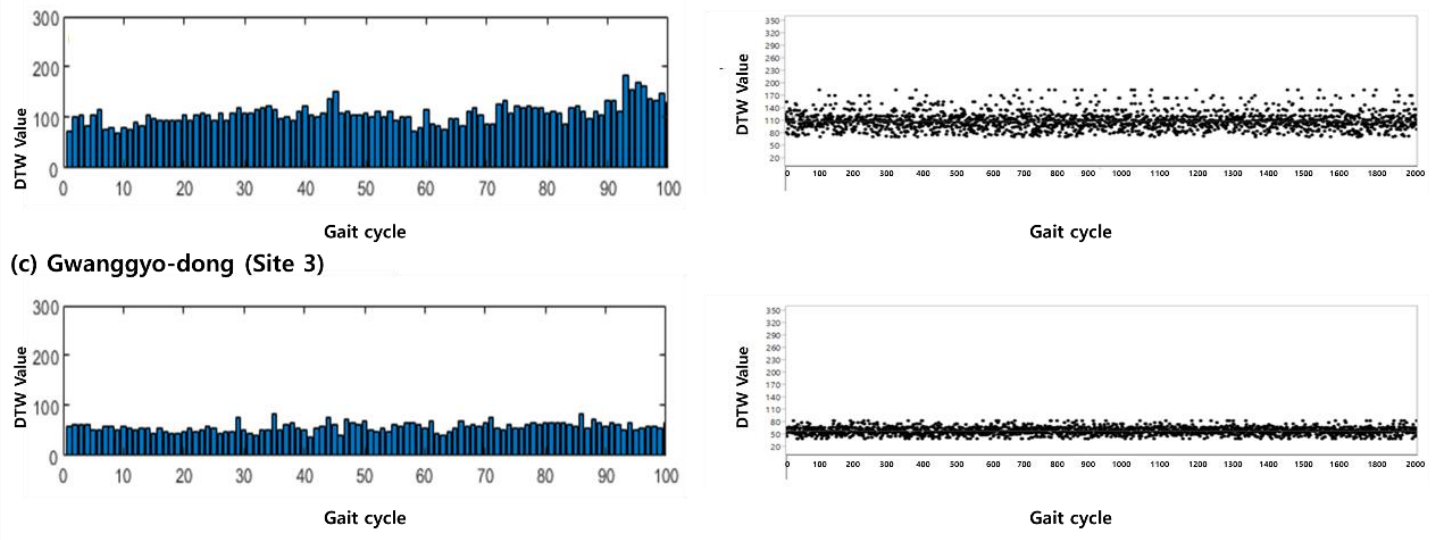

Figure 6. DTW visualization using bar chart and scatter plot: (a) Sangdaewon-dong (Site1); (b) Jeongja-dong (Site2); (c) Gwanggyo-dong (Site3).

\subsection{Analysis of DTW}

DTW was calculated to examine the similarity of the gait cycle of the reference walking obtained above and the gait cycle at each site (Site1, Sangdaewon-dong/Site2, Jeongja-dong/Site3, 
Gwanggyo-dong). A DTW value closer to 0 indicates that the gait pattern is similar to that in the reference walking and hence, the degree of walkability can be indirectly inferred according to the DTW value.

If you visualize the data at each site through bar charts and scatter plots, you can easily check the change in DTW values. Figure 7 shows the previously calculated DTW value. In the bar chart, the $x$-axis represents the gait cycle and the y-axis represents the DTW value. In the scatter plot, the $x$-axis represents all walks by site and the y-axis represents the DTW values, i.e., those in the bar charts. First, it can be observed from the bar chart that Sangdaewon-dong (Site1) has a marked change compared with Jeongja-dong (Site2) and Gwanggyo-dong (Site3).

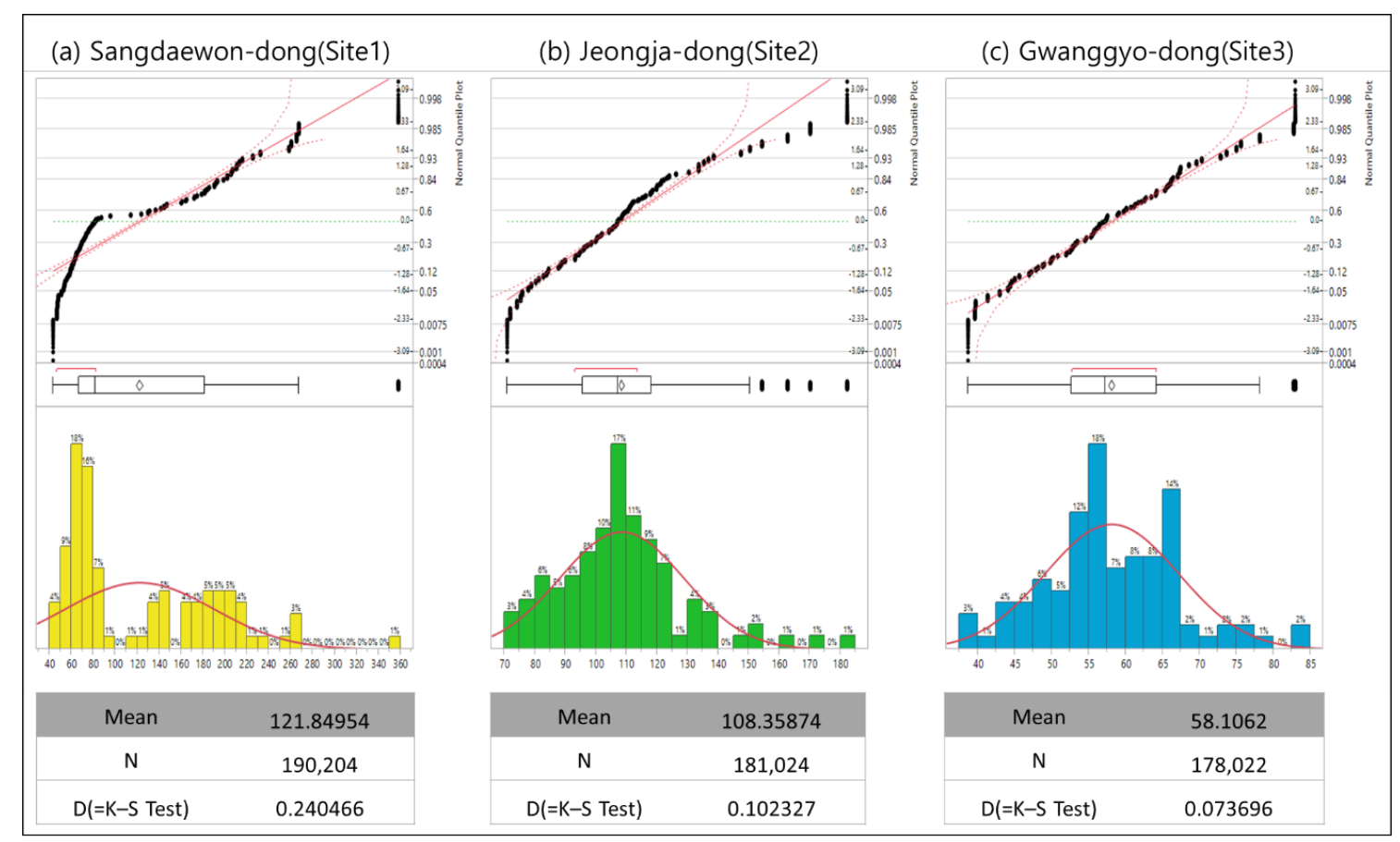

Figure 7. Normality test results—-histogram and Q-Q plot: (a) Sangdaewon-dong (Site1); (b) Jeongja-dong (Site2); (c) Gwanggyo-dong (Site3).

The graph shows that the change in the DTW value of Sangdaewon-dong is larger than that of Jeongja-dong and Gwanggyo-dong. Sangdaewon-dong shows a steep change ranging from 50 to 350. Sangdaewon-dong was the first city to be built (in the 1970s) among the three experimental sites. This period preceded the expansion of the pedestrian policy and the purpose of the road was to secure a minimum connection. In addition, the road was planned to be focused on vehicles rather than pedestrians. Therefore, as the road was not intended for pedestrians, there was no separation of pedestrians and cars and motorcycles were parked and stopped on the road in several cases. In addition, cracks in the road occurred after several years of construction and several elements, such as garbage, hindered walking. It can be inferred that the physical influence of the factors that obstruct walking causes a change in the movement of the pedestrians and the calculated value of DTW also changes significantly.

In the scatter plot, the x-axis represents all walks by site and the y-axis represents the DTW values, i.e., those in the bar charts. First, it can be observed from the bar chart that Sangdaewon-dong (Site1) has a marked change compared with Jeongja-dong (Site2) and Gwanggyo-dong (Site3). In the scatter plot, the gait DTW value in Sangdaewon-dong (Site1) is not distributed as a constant value, but various values are distributed; in contrast, it can be observed that constant values are distributed toward Jeongja-dong and Gwanggyo-dong. That is, in Sangdaewon-dong (Site1), the consistency of gait is not maintained, whereas the DTW values are consistent in Jeongja-dong and Gwanggyo-dong. 
Therefore, the more recent the walking environment is, the more consistent is the gait and consequently, the walkability can be considered excellent.

\subsection{Analysis of K-S Test}

A normality test is used to test whether a dataset follows a normal distribution. In this study, the normality of DTW for each experimental site was tested using the K-S test, which is used to test the normality of a large dataset. The closer the test result is to 0 , the more normal the dataset is; thus, the walkability of the corresponding area can be analyzed by determining whether the gait data are consistent.

Figure 8 shows the results of the normality test performed using the K-S test for the DTW data value of the total walking steps for each site. The total numbers of walking steps of the 30 people who participated in the experiment were 190,204, 181,024 and 178,022 in Sangdaewon-dong, Jeongja-dong and Gwanggyo-dong, respectively. The K-S values for DTW at each site were 0.2404 for the relative source, 0.1023 for Jeongja-dong and 0.0736 for Gwanggyo-dong. The closer the K-S value was to 0 , the higher was the normality, which indicates that the gait was constant. Therefore, Gwanggyo-dong has the most consistent gait, followed by Jeongja-dong and Sangdaewon-dong in that order. In other words, it was confirmed that the test value decreased and the consistency of gait increased, as the built period of the city became more recent.

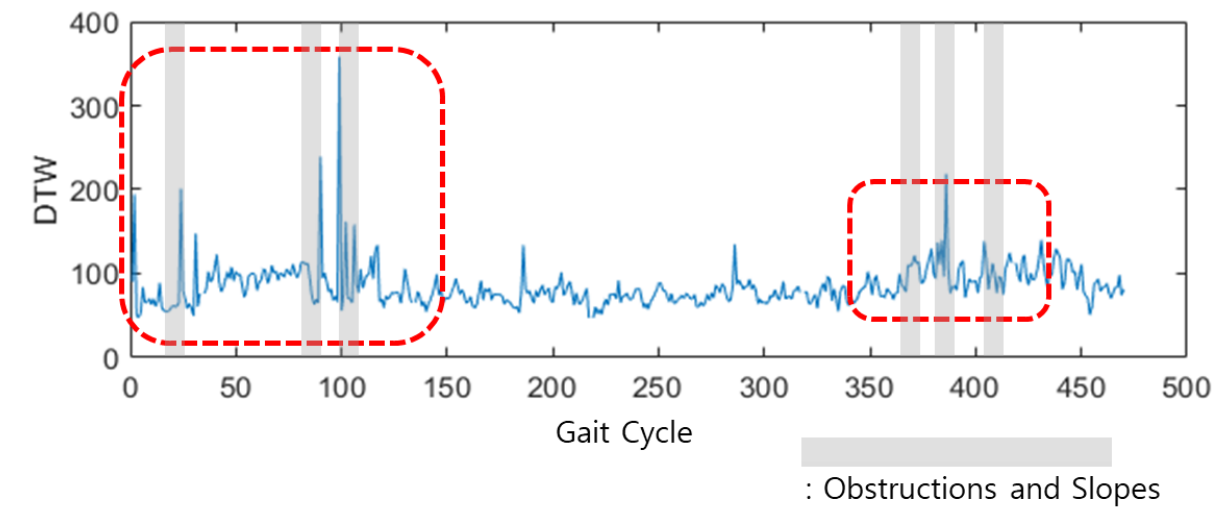

Figure 8. Average value of DTW changes in partial section of Site1.

Figure 8 shows the $\mathrm{Q}-\mathrm{Q}$ plot and histogram for each site. In the case of the relative driving force, the $\mathrm{Q}-\mathrm{Q}$ plot shows several distribution values far from the straight line, which indicates that the normality is low. In histograms without a general normal distribution, one side is largely distributed and several irregularities are observed. Therefore, the gait pattern in Sangdaewon-dong was not constant and the result of the above graph can be estimated to be due to external environmental factors that may hinder the uniformity of gait. Next, a graph analysis of Jeongja-dong and Gwanggyo-dong is performed. In the case of the $\mathrm{Q}-\mathrm{Q}$ plot, the static automatic distribution shows a slight deviation from the straight line, but a uniform straight line is generally formed. This indicates that, although there is a section outside the section maintained constant, the normality is high and the gait cycle is maintained within a certain range. Gwanggyo-dong has almost the same distribution as a straight line. Therefore, it can be said that Gwanggyo-dong has the highest normality compared with the other two cities.

The histogram of Jeongja-dong appears to follow a normal distribution more closely compared with Gwanggyo-dong. However, it can be confirmed that Gwanggyo-dong has a lower K-S value than Jeongja-dong and thus has a higher normality. Jeongja-dong appears to follow a normal distribution more closely than Gwanggyo-dong because similar K-S values are distributed. However, as indicated by the x-axis, Jeongja-dong has a wider DTW range (70-180) than Gwanggyo-dong (40-80). This indicates that Jeongja-dong has a larger gait change and is less consistent than Gwanggyo-dong. In addition, 
as there are relatively more gait sections with a large variation, the normality of Gwanggyo-dong is numerically higher.

The test shows that Gwanggyo-dong has the highest normality, followed by Jeongja-dong and relative Wondong in that order. That is, as Gwanggyo-dong has the most constant gait pattern, it can be confirmed that walking in Gwanggyo-dong, which has a normality according to the hypothesis previously assumed, is most convenient. In the case of Sangdaewon-dong, the graph also shows a significant change and the K-S value is the lowest, which indicates that the consistency of gait cannot be maintained. Therefore, its walkability is the lowest among the three sites.

Thus, the most recently built site is considered to have higher walkability. Therefore, it was confirmed that efforts to enhance citizens' right to walk have been continuously made over time and that laws and policies to ensure walkability have been implemented.

\section{Discussions}

Previous sections showed that the DTW and K-S test statistics can be used to measure the walkability in different walking environments by utilizing the collective body response of pedestrians. This section investigates (1) the changes in gait due to the changes in the walking environment, (2) the significance of including actual users in the measurement of walkability, (3) monitoring of regional walking environment improvement projects and enhancing policy effectiveness and 4) limitations of the study and future research directions.

\subsection{Changes in Gait due to Changes in the Walking Environment}

The key factor for evaluating walkability is the reaction of the pedestrians' body according to their interaction with the walking environment. Specifically, this study determined that the distribution of the pedestrians' body response can be used to estimate the factors that affect gait patterns in the walking environment. When a pedestrian walks on a walking path, the walking environment can affect the pedestrian's body reaction. Moreover, when there are no significant changes in the walking environment, the gait pattern is consistent and regular. In other words, in a normal walking environment (condition), pedestrians do not change their gait pattern suddenly [44]. When regular patterns collected from several pedestrians overlap at a specific location, the distribution of body responses with high normality can be expressed.

Figure 9 shows the average value of DTW changes in some sections of Sangdaewon-dong. The DTW value changes in sections where there is an obstruction or slope. It can be observed that walking obstructions and slopes change the movement of pedestrians, causing changes in walking. Furthermore, these environmental changes affect the pedestrian's body movement and they are reflected in gait.

\subsection{Significance of Including Real Users in the Measurement of Walkability}

The method proposed in this study does not replace the existing method of measuring walkability. Pedestrianism includes various concepts, such as population density, land use, street type, sidewalk extent and vehicle traffic [45]. These concepts affect walkability. Therefore, this study proposed a method of integrating and utilizing the behavior of real users that can be used as an additional support tool for the existing method. The result can improve walking performance by analyzing the built walking environment. For example, incorporating real user behavior into gait measurements may have additional advantages over current vision-based methods, such as detecting potholes or cracked bricks. Existing vision-based methods analyze images using machine learning or artificial intelligence and subsequently, cracks and potholes are efficiently detected. Nevertheless, as the vision-based methods are developed based on how cracks and potholes are determined by existing regulations, they do not estimate how the actual user reacts to the detected cracks and potholes. Therefore, the method proposed in this study can fill the gap between the current gait measurement and the integration of 
real user behavior. In addition, pedestrian behavior on a pedestrian path can be used to provide an additional method of measuring the current gait.

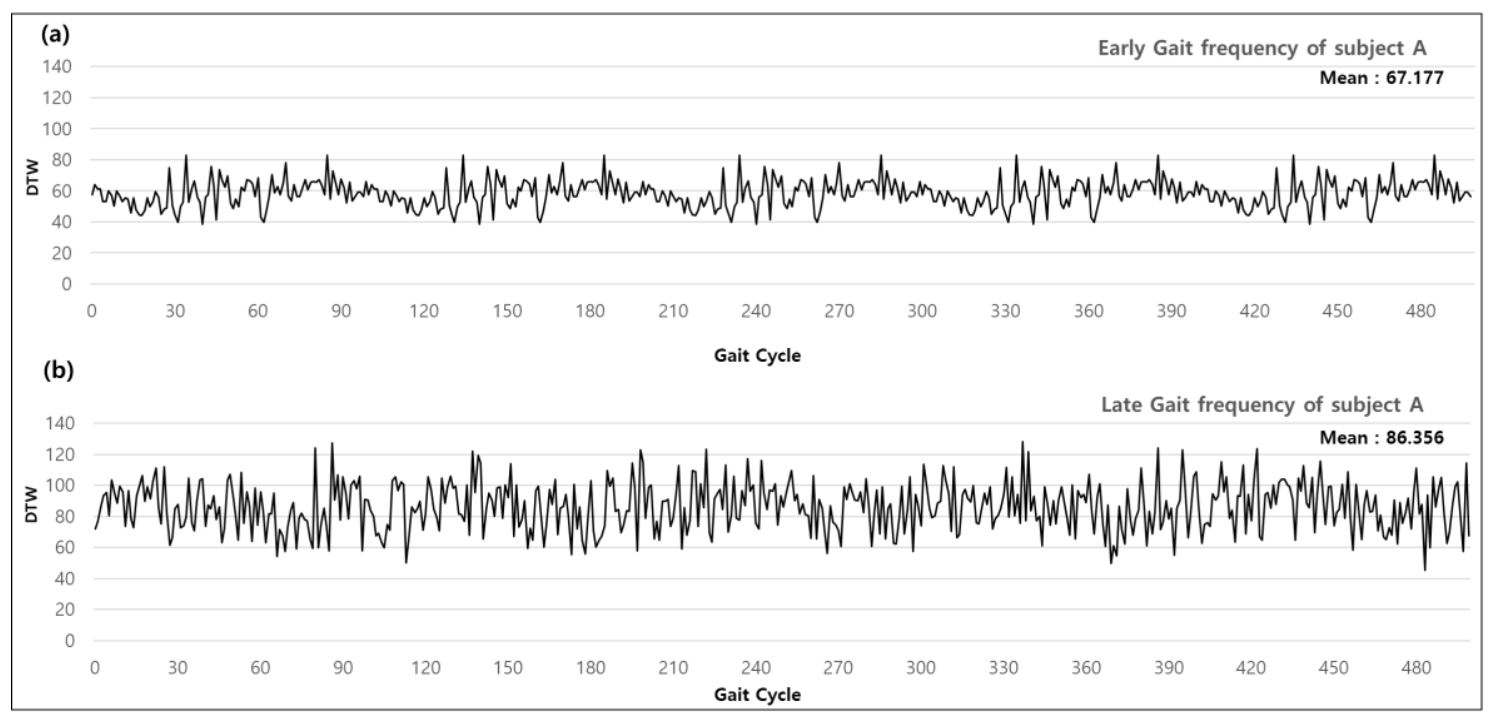

Figure 9. Changes in DTW value according to fatigue: (a) Early gait frequency of Subject A; (b) late gait frequency of Subject A.

Current gait measurements are usually performed by inspectors trained at government agencies [13]. Despite the importance of the walking environment, the gap between inspections is generally long, due to staffing and budget constraints. Therefore, the current measurement method does not adapt well to changes in the walking environment. Contrary to current practice, the measurement method presented in this paper measures gait based on a pedestrian's body response. When a participating pedestrian walks, an immediate body reaction is collected to measure the gait. In addition, the aggregate data of pedestrians can be continuously measured for comparison. In addition, the daily activities of humans can be used to monitor urban environments continuously based on the results of this study. Considering the high usage of smartphones across all generations, this study can contribute to monitoring and evaluating gait from the perspective of smart cities and citizen sensing. As such, a tool that can collect and transmit data is required to introduce the concept of project reporting to this study. Human behavior is continuously monitored through sensors, such as smartphones. Then, the collected data are analyzed and information on urban environments in need of improvement is delivered to the relevant organizations. Accordingly, the relevant organizations improve the environments. This requires sensors that collect and transmit citizen data. Consequently, a smartphone was selected to collect data on the subjects' gait behavior in this study. The reasons for choosing a smartphone among various wearable devices are as follows. First, a smartphone can collect information on the walking behavior of a subject using an IMU sensor. Second, most smartphones have the ability to specify their own location. In particular, as walking is mainly performed outdoors, the location of the subject can be specified through the GPS capability of the smartphone. Finally, as smartphones can transmit and receive data, the field of urban environment monitoring can be investigated further in the future.

\subsection{Monitoring of Regional Walking Environment Improvement Projects and Enhancing Policy Effectiveness}

This evaluation model can be used to evaluate the quantitative effects of the projects promoted by the government. Consequently, a database of the evaluated data can be built. Currently, effectiveness evaluation is conducted after project implementation through literature and data research, questionnaire surveys, etc., focusing on evaluation indicators. However, there is a high tendency to rely on questionnaire surveys, which have the disadvantage of a wide variation in application as an objective 
evaluation index. Therefore, as the model proposed in this study has objectivity, it can be introduced as a quantitative evaluation method. In particular, the model needs to be standardized for its use as a tool to improve the effectiveness of regional walking environment improvement project monitoring and to enhance policy effectiveness. In other words, the method presented in this study can be used as a quantitative evaluation tool that enables continuous monitoring and consulting of projects and policies supported by the central government. It is also possible to measure links to future improvement projects and planned projects.

\subsection{Possibility of Evaluation Method for Walkability in Long Term Units}

Walkability is affected by various factors such as internal factors (e.g., age, gender, physical ability of individual) and external environmental factors (e.g., road type, type of pedestrian facility). In previous studies, the previous walkability measurement method used surveys [46] and developed evaluating tools $[13,14]$. Although these methods can incorporate various factors affecting walkability, there may be a possibility to involve subjective judgement in the evaluation process. Therefore, in this study, walkability is indicated by evaluating the gait stability of pedestrians' immediate body response, so subjective tendency can be minimized. In another study, Kim [47] divided the road conditions into four categories: pedestrian walkway, sidewalk (no illegal parking), mixed traffic road (no sidewalk with illegal parking) and sidewalk (illegal parking on sidewalk). In determining the walkability of pedestrians, Kim [47] focused on the local body stability measured by Maximum Lyapunov exponent (MaxLE) to determine kinematic variability (dynamic stability). MaxLE is an algorithm that can indicate the sensitivity of changes and is mainly used to identify changes in posture such as local body stability [48]. Therefore, MaxLE is useful for grasping momentary changes. For example, when a crack exists in the pedestrian path, the pedestrian avoids the crack and causes an immediate change in physical movement, so MaxLE can be used to calculate this movement. Therefore, the MaxLE algorithm can an advantageous tool for grasping walking stability in the short-ranged street rather than the long-ranged street. However, this study is conducted to confirm the relationship between walkability and historical policy changes. In this study, each subject walked at least $3 \mathrm{~km}$. Therefore, grasping and analyzing the similarity of the gait pattern of each site (by environment) can show changes in the overall urban environment. Therefore, this study compared the walking environment using the DTW algorithm, which can quantitatively compare similarity using time series data.

\subsection{Positioning of Wearable Sensors and Influence Factors of Gait Stability}

Wearable sensors attached to the body can be a tool that helps to identify physical characteristics. Smartphones can be placed in the hands (hand-held condition), legs (carried in pants pocket), waist or inside a jacket. Two attachment locations can be considered examples: the first case is that a smartphone is attached to the wrist; the second case is that a smartphone is attached to the leg. In this comparison of two cases, the changes of patterns is more significant in the wrist attached case, since the IMU sensor collects the movements which are the results of the combined movements of the body and arm. Another factor related to the positioning of wearable sensors is the tightness of attachment. Even though the attachment location is same, the collected data include different degrees of noise according to the tightness of attachment. For example, there are clear differences between the case when a subject puts a smartphone in a pants pocket (higher noise) and the case when a smartphone is firmly attached over a pants pocket (lower noise). Frequent noise occurrence may cause errors in the process of comparing data. Therefore, in future studies, the noise from different attachment locations and tightness should be more examined. Walkability can be an index affected by various factors. Not only the condition of the road, but also the individual walking characteristics can be different. For example, even with the same path, the walkability felt by young people and the elderly may be different. Although it is important to incorporate individual characteristics in the walkability measurement, this study aims to confirm the relationship between walkability and historical policy changes. Therefore, in order to minimize the impact on individuality, the participants were recruited mainly in their 20s and 40s, who were judged 
to have sufficient walking ability. In previous studies, different walking ability between younger and older people was found. With increasing age, gait instability begins to accelerate [49], in addition to general physical capability (e.g., physical capability, gender, swing angle) [50,51]. Therefore, in future studies, it is necessary to conduct a study on how to (1) apply the individual's characteristics to walkability measurement and (2) integrate individual walkability collectively. Walkability can be seen as an index that is affected by a wide variety of factors. Not only the condition of the road, but also the characteristics of the individual walking the road can be sufficiently different.

\subsection{Limitations of the Study and Future Research}

This study explored the feasibility of adopting physiological sensing for gait measurement. Although the results support the feasibility of the proposed method, its direct application in the real world may be limited. In this study, the IMU sensor built into the smartphone was placed in the side pocket of the pants of the participants, similar to a previous study. However, the participants in this study did not have a uniform body shape. This generated considerable noise in the data as the smartphone was shaken due to the difference in the location of the pocket or in body shape. Therefore, future studies should address this problem by applying a filtering method. In addition, other factors affecting pedestrian performance, such as population density and land-use heterogeneity, need to be investigated. Our experiments focused only on the disturbances on certain roads or walkways. However, other factors should be included in the gait measurement because a pedestrian's body response is affected not only by specific road conditions but also by the surrounding construction environment. In addition, the fatigue degree was not considered in the experiment. The participants in this study walked for at least $3 \mathrm{~km}$. At this time, as no measures were taken to mitigate fatigue, with the progress of the experiment, the fatigue affected physical mobility, which affected the gait [52]. Therefore, various factors affecting walkability, such as fatigue, need to be investigated further in future studies.

\section{Conclusions}

Efforts have been made to increase the walkability of pedestrians in cities. Various pedestrian-related laws and policies have been implemented to improve walkability. However, although various walkability policies have been implemented, the quantitative measurement of walkability was insufficient in previous studies. Therefore, in this study, the limitations of previous studies were overcome and the walkability was quantitatively expressed by analyzing the walkability index of three sites (Sangdaewon-dong, Jeongja-dong and Gwanggyo-dong) with different creation periods using the wearable sensor of a smartphone. The applicability of pedestrian-related laws and policies was confirmed through the index.

Accordingly, Sangdaewon-dong, Jeongja-dong and Gwanggyo-dong were selected as test sites based on Seongnam-si and 30 adults in their 20s to 40 s were recruited for participation in the experiment. Gait data were collected using the IMU sensor of smartphones and accordingly, a numeric DTW value was calculated through DTW analysis. The difference in the walkability index could be expressed quantitatively using the DTW value and the applicability of the pedestrian laws and policies could be confirmed.

The pedestrian policy performance index evaluation system using DTW is expected to be much more economical and efficient than the existing evaluation system, which requires a high cost and a long period of time. The proposed method can be used as an objective evaluation tool. The evaluation results of this study are expected to contribute to the gait evaluation system using citizen sensing in smart cities in the future.

However, in this study, the IMU sensor built into the smartphone was placed in the side pocket of the pants of the participants, similar to a previous study. Similar to the results of the previous study, the difference between sites could be confirmed by the data collected by the smartphone placed in the pants. However, better results can be obtained if the noise generated by the smartphone shaking inside the pants can be corrected while walking. In addition, other factors that affect walkability, such as 
population density and land-use heterogeneity, need to be investigated further. Our experiments focused only on the disturbances on certain roads or walkways. However, other factors should be included in the measurement of walkability because the pedestrian's body response is affected not only by specific road conditions but also by the surrounding construction environment. Thus, in future studies, additional factors that affect walkability need to be investigated. In the future, studies should be conducted to secure a large number of samples on pedestrian paths in various use areas and to verify additional influencing factors.

Author Contributions: Conceptualization: J.Y. and H.K.; methodology: J.Y. and J.C.; validation: J.Y., J.C., and H.K.; writing—original draft preparation: J.Y. and H.K.; writing—review and editing: H.K.; visualization: J.Y. and J.C.; supervision: H.K.; project administration: H.K.; funding acquisition: H.K. All authors have read and agreed to the published version of the manuscript.

Funding: This research was supported by Basic Science Research Program through the National Research Foundation of Korea (NRF) funded by the Ministry of Education (NRF-2018R1D1A1B07048638).

Conflicts of Interest: The author declares no conflict of interest.

\section{References}

1. Litman, T.A. Economic Value of Walkability. Transp. Res. Rec. J. Transp. Res. Board 2003, 1828, 3-11. [CrossRef]

2. Abley, S. Walkability Scoping Paper; Abley Transportation Consultants: Christchurch, New Zealand, 2005.

3. Bhardwaj, P. Working Paper Series the Pedestrian and the Road. Cent. Public Polciy Res. 2010, 33, 6-14.

4. Kim, E.; Kim, I.; Yeong, M.; So, G.; Lim, S.; Jeong, S.; Jo, J. The Improvement of the Pedestrian Environment in Korea Policies and Achievements. Available online: http://www.dbpia.co.kr/pdf/pdfView.do?nodeId= NODE06335316\&mark=0\&useDate=\&bookmarkCnt=0\&ipRange=N\&accessgl=Y\&language=ko_KR (accessed on 3 April 2020).

5. Kim, S.; Son, D. Improvement of Pedestrian Safety and Convenience Enhancement Act. Public Policy Res. 2015, 2015, 1-225.

6. Oh, S.; Kim, J.; Park, Y.-S. Assessing Legal Issues for Pedestrian Priority Street in Korea. J. Korea Plan. Assoc. 2014, 49, 79-90. [CrossRef]

7. Kim, G.R.; Lee, J. Pedestrian Cognition and Satisfaction on the Physical Elements in Pedestrian Space. J. Urban Des. Inst. Korea 2016, 17, 89-103.

8. Park, S.; Choi, Y.; Seo, H. Measuring Walkability in Urban Residential Neighborhoods: Development of Walkability Indicators. Available online: http://www.auric.or.kr/User/Rdoc/DocRdoc.aspx?returnVal=RD_ R\&dn=215493\#.X9apwNj7RiA (accessed on 3 April 2020).

9. Adams, M.A.; Todd, M.; Kurka, J.; Conway, T.L.; Cain, K.L.; Frank, L.D.; Sallis, J.F. Patterns of Walkability, Transit, and Recreation Environment for Physical Activity. Am. J. Prev. Med. 2015, 49, 878-887. [CrossRef] [PubMed]

10. Wey, W.-M.; Chiu, Y.-H. Assessing the walkability of pedestrian environment under the transit-oriented development. Habitat Int. 2013, 38, 106-118. [CrossRef]

11. Daamen, W.; Hoogendoorn, S.P. Experimental Research of Pedestrian Walking Behavior. Transp. Res. Rec. 2003, 1828, 20-30. [CrossRef]

12. Singh, R. Factors Affecting Walkability of Neighborhoods. Procedia Soc. Behav. Sci. 2016, 216, $643-654$. [CrossRef]

13. Clifton, K.J.; Livi Smith, A.D.; Rodriguez, D. The development and testing of an audit for the pedestrian environment. Landsc. Urban Plan. 2007, 80, 95-110. [CrossRef]

14. Hoehner, C.M.; Ivy, A.; Ramirez, L.K.B.; Handy, S.; Brownson, R.C. Active Neighborhood Checklist: A User-Friendly and Reliable Tool for Assessing Activity Friendliness. Am. J. Health Promot. 2007, 21, 534-537. [CrossRef] [PubMed]

15. Blečić, I.; Congiu, T.; Fancello, G.; Trunfio, G.A. Planning and Design Support Tools for Walkability: A Guide for Urban Analysts. Sustainability 2020, 12, 4405. [CrossRef] 
16. Ahmed, A.; Yasumoto, K.; Yamauchi, Y.; Ito, M. Distance and time based node selection for probabilistic coverage in People-Centric Sensing. In Proceedings of the 2011 8th Annual IEEE Communications Society Conference on Sensor, Mesh and Ad Hoc Communications and Networks, Salt Lake City, UT, USA, 27-30 June 2011; pp. 134-142.

17. Campbell, A.T.; Eisenman, S.B.; Lane, N.D.; Miluzzo, E.; Peterson, R.A.; Lu, H.; Zheng, X.; Musolesi, M.; Fodor, K.; Ahn, G.-S. The Rise of People-Centric Sensing. IEEE Internet Comput. 2008, 12, 12-21. [CrossRef]

18. Tao, W.; Liu, T.; Zheng, R.; Feng, H. Gait Analysis Using Wearable Sensors. Sensors 2012, 12, $2255-2283$. [CrossRef] [PubMed]

19. Kim, H.; Ahn, C.R.; Yang, K. Identifying Safety Hazards Using Collective Bodily Responses of Workers. J. Constr. Eng. Manag. 2017, 143, 04016090. [CrossRef]

20. Olguin, D.O. Social Sensors for Automatic Data Collection. Available online: https://aisel.aisnet.org/cgi/ viewcontent.cgi? article $=1179 \&$ context=amcis2008 (accessed on 4 April 2020).

21. Waber, B.N.; Olguín, D.O.; Kim, T.; Pentland, A. Understanding Organizational Behavior with Wearable Sensing Technology. Available online: https://papers.ssrn.com/sol3/papers.cfm?abstract_id=1263992 (accessed on 6 April 2020).

22. Mukhopadhyay, S.C. Wearable Sensors for Human Activity Monitoring: A Review. IEEE Sens. J. 2015, 15, 1321-1330. [CrossRef]

23. Jalal, A.; Quaid, M.A.K.; Hasan, A.S. Wearable Sensor-Based Human Behavior Understanding and Recognition in Daily Life for Smart Environments. In Proceedings of the 2018 International Conference on Frontiers of Information Technology (FIT), Islamabad, Pakistan, 17-19 December 2018; pp. 105-110.

24. Qin, Z.; Zhang, Y.; Meng, S.; Qin, Z.; Choo, K.-K.R. Imaging and fusing time series for wearable sensor-based human activity recognition. Inf. Fusion 2020, 53, 80-87. [CrossRef]

25. Wang, X.; Kyrarini, M.; Ristić-Durrant, D.; Spranger, M.; Gräser, A. Monitoring of gait performance using dynamic time warping on IMU-sensor data. In Proceedings of the 2016 IEEE International Symposium on Medical Measurements and Applications (MeMeA), Benevento, Italy, 15-18 May 2016; pp. 1-6.

26. An, K.H.; Kim, E.T.; Ryu, U.J.; Chang, Y.S. Implementation on SVM based Step Detection Analyzer. J. Korea Multimed. Soc. 2013, 16, 1147-1155. [CrossRef]

27. Asarian, L.; Gloy, V.; Geary, N. Homeostasis. In Encyclopedia of Human Behavior, 2nd Ed.; Ramachandran, V.S., Ed.; Academic Press: San Diego, CA, USA, 2012; pp. 324-333. ISBN 978-0-08-096180-4.

28. Handy, S.; Cao, X.; Mokhtarian, P.L. Self-Selection in the Relationship between the Built Environment and Walking: Empirical Evidence from Northern California. J. Am. Plann. Assoc. 2006, 72, 55-74. [CrossRef]

29. Forsyth, A.; Michael Oakes, J.; Lee, B.; Schmitz, K.H. The built environment, walking, and physical activity: Is the environment more important to some people than others? Transp. Res. Part Transp. Environ. 2009, 14, 42-49. [CrossRef]

30. Rafiemanzelat, R.; Emadi, M.I.; Kamali, A.J. City sustainability: The influence of walkability on built environments. Transp. Res. Procedia 2017, 24, 97-104. [CrossRef]

31. Kim, H.; Ahn, C.R.; Yang, K. A people-centric sensing approach to detecting sidewalk defects. Adv. Eng. Inform. 2016, 30, 660-671. [CrossRef]

32. Decker, L.; Houser, J.J.; Noble, J.M.; Karst, G.M.; Stergiou, N. The effects of shoe traction and obstacle height on lower extremity coordination dynamics during walking. Appl. Ergon. 2009, 40, 895-903. [CrossRef] [PubMed]

33. Muro-de-la-Herran, A.; Garcia-Zapirain, B.; Mendez-Zorrilla, A. Gait Analysis Methods: An Overview of Wearable and Non-Wearable Systems, Highlighting Clinical Applications. Sensors 2014, 14, 3362-3394. [CrossRef]

34. Im, S. People-Centered Green Transportation: Securing Pedestrian Rights; Korea Research Institute for Human Settlements: Sejong Special Self-Governing City, Korea, 2012; pp. 50-58.

35. Maggiore, G.; Santos, C.; Plaat, A. Smarter Smartphones: Understanding and Predicting User Habits from GPS Sensor Data. Procedia Comput. Sci. 2014, 34, 297-304. [CrossRef]

36. Lue, G.; Miller, E.J. Estimating a Toronto pedestrian route choice model using smartphone GPS data. Travel Behav. Soc. 2019, 14, 34-42. [CrossRef]

37. Lee, S.-M.; Hwang, G.-Y. Effect of Walking-Environment Factor on Pedestrian Safety. J. Korean Soc. Transp. 2009, 27, 107-114. 
38. Patel, M.; Pavic, A.; Goodwin, V.A. Wearable inertial sensors to measure gait and posture characteristic differences in older adult fallers and non-fallers: A scoping review. Gait Posture 2020, 76, 110-121. [CrossRef]

39. Höflinger, F.; Müller, J.; Zhang, R.; Reindl, L.M.; Burgard, W. A Wireless Micro Inertial Measurement Unit (IMU). IEEE Trans. Instrum. Meas. 2013, 62, 2583-2595. [CrossRef]

40. Bidargaddi, N.; Sarela, A.; Klingbeil, L.; Karunanithi, M. Detecting walking activity in cardiac rehabilitation by using accelerometer. In Proceedings of the Sensor Networks and Information 2007 3rd International Conference on Intelligent Sensors, Melbourne, QLD, Australia, 3-6 December 2007; pp. 555-560.

41. Al-Naymat, G.; Chawla, S.; Taheri, J. SparseDTW: A Novel Approach to Speed up Dynamic Time Warping. Available online: https://arxiv.org/pdf/1201.2969v1.pdf (accessed on 6 April 2020).

42. Boulgouris, N.V.; Plataniotis, K.N.; Hatzinakos, D. Gait recognition using dynamic time warping. In Proceedings of the IEEE 6th Workshop on Multimedia Signal Processing, Siena, Italy, 29 September-1 October 2004; pp. 263-266.

43. Benbakreti, S.; Benyettou, M. Recognition Human by Gait using PCA, DTW. In Proceedings of the CIIA, Saida, Algeria, 13-15 December 2011.

44. Wang, J.-S.; Lin, C.-W.; Yang, Y.-T.C.; Ho, Y.-J. Walking Pattern Classification and Walking Distance Estimation Algorithms Using Gait Phase Information. IEEE Trans. Biomed. Eng. 2012, 59, 2884-2892. [CrossRef]

45. Weiss, A.; Shimkin, I.; Giladi, N.; Hausdorff, J.M. Automated detection of near falls: Algorithm development and preliminary results. BMC Res. Notes 2010, 3, 62. [CrossRef] [PubMed]

46. Owen, N.; Cerin, E.; Leslie, E.; duToit, L.; Coffee, N.; Frank, L.D.; Bauman, A.E.; Hugo, G.; Saelens, B.E.; Sallis, J.F. Neighborhood Walkability and the Walking Behavior of Australian Adults. Am. J. Prev. Med. 2007, 33, 387-395. [CrossRef] [PubMed]

47. Kim, H. Wearable Sensor Data-Driven Walkability Assessment for Elderly People. Sustainability 2020, $12,4041$. [CrossRef]

48. Liu, J.; Zhang, X.; Lockhart, T.E. Fall Risk Assessments Based on Postural and Dynamic Stability Using Inertial Measurement Unit. Saf. Health Work 2012, 3, 192-198. [CrossRef]

49. Terrier, P.; Reynard, F. Effect of age on the variability and stability of gait: A cross-sectional treadmill study in healthy individuals between 20 and 69 years of age. Gait Posture 2015, 41, 170-174. [CrossRef]

50. Ko, S.; Tolea, M.I.; Hausdorff, J.M.; Ferrucci, L. Sex-specific differences in gait patterns of healthy older adults: Results from the Baltimore Longitudinal Study of Aging. J. Biomech. 2011, 44, 1974-1979. [CrossRef]

51. Bruijn, S.M.; Meijer, O.G.; Beek, P.J.; van Dieën, J.H. The Effects of Arm Swing on Human Gait Stability. J. Exp. Biol. 2010, 213, 3945-3952. Available online: https://jeb.biologists.org/content/213/23/3945 (accessed on 1 December 2020). [CrossRef]

52. Jorunn, L.H.; Sara, L.; Rolf, M.-N. Physical Fatigue Affects Gait Characteristics in Older Persons. J. Gerontol. A 2007, 62, 1010-1015.

Publisher's Note: MDPI stays neutral with regard to jurisdictional claims in published maps and institutional affiliations.

(C) 2020 by the authors. Licensee MDPI, Basel, Switzerland. This article is an open access article distributed under the terms and conditions of the Creative Commons Attribution (CC BY) license (http://creativecommons.org/licenses/by/4.0/). 